\title{
Penerapan Sistem Antrian Registrasi Dengan Metode Multi Channel-Multi Phase
}

\author{
${ }^{*}$ Antonius purba ${ }^{1}$, Insan taufik ${ }^{2}$ \\ 1,2STMIK Pelita Nusantara, Teknik Informatika, Indonesia \\ antoniuspurba26@gmail.com ${ }^{1}$,insan.taufik@gmail.com²
}

\begin{abstract}
Abstrak
Dalam memberikan pelayanan sistem antrian pasien di rumah sakit masih banyak ditemukan kendala dalam proses antrian, diantaranya penumpukan pasien saat mengambil nomor antrian, antrian yang terlalu banyak dalam sistem antrian dan lamanya waktu menunggu dalam sistem antrian sehingga proses antrian dianggap memperlambat proses pelayanan. Oleh sebab itu penulis mengembangkan sistem antrian yang dilengkapi dengan jalur masuk pelayanan yang banyak dan sistem pelayanan yang banyak yang disebut dengan sistem antrian multi channel - multi phase. Penerapan model antrian multi channel - multi phase membuat aplikasi dapat melayani lebih dari satu jenis layanan di rumah sakit dan dengan jalur masuk yang banyak yang dapat disesuaikan dengan jenis dan jumlah unit pelayanan. Aplikasi antrian ini juga dilengkapi dengan pemanggil suara seperti aplikasi antrian yang telah ada saat ini dan bisa dilakukan perubahan atau penambahan jumlah dan jenis layanan sewaktu-waktu sesuai kebutuhan rumah sakit.
\end{abstract}

\section{Keywords - queue, hospital, multi-channel multi-phase.}

\section{Latar Belakang}

Permasalahan yang sering terjadi ketika pelayanan pendaftaran berlangsung di sebuah rumah sakit adalah terjadinya penumpukan calon pasien ketika mengambil nomor antrian dan saat mendaftar. Penumpukan antrian calon pasien juga mengakibatkan ruang tunggu yang tersedia tidak memadai lagi, hal tersebut terjadi karena tidak ada suatu jalur disiplin yang dapat memberikan suatu bentuk pelayanan pendaftaran yang efesien dan fleksibel terhadap waktu dengan banyak jalur masuk dan banyak pelayanan sehingga pasien tidak harus mengantri panjang hanya untuk mengambil nomor antrian dan mendaftar.

Solusi penanganan masalah penumpukan calon pasien di RSU Royal Prima adalah dengan menerapkan sistem antrian multi channel - multi phase, dimana akan ada lebih dari satu jalur masuk untuk melakukan pendaftaran ke RSU Royal Prima sehingga pola kedatangan pasien terbagi menjadi beberapa waktu dan jalur yang disesuaikan dengan kebutuhan waktu yang diinginkan pasien dan terdapat lebih dari satu tahap pelayanan di RSU Royal Prima.

Teori tentang antrian pertama kali ditemukan dan dikembangkan oleh A.K Erlang (1913) yang mempelajari fluktuasi permintaan telepon dan keterlambatan pelayanannya [3]. Menurut Hamdy Toha (1997), proses antrian adalah suatu proses yang berhubungan dengan kedatangan pelanggan pada suatu fasilitas pelayanan kemudian menunggu dalam baris antrian jika belum dapat dilayani, kemudian dilayani, dan akhirnya meninggalkan fasilitas tersebut setelah dilayani [1].

Menurut Toibah Umi Kalsum dan Siswanto sistem adalah sebuah tatanan (keterpaduan) yang terdiri atas sejumlah komponen dengan satu fungsi atau tugas khusus yang saling berhubungan dan secara bersama-sama untuk melakukan suatu kegiatan atau menyelesaikan suatu masalah tertentu [6]. Antrian adalah tersusun dengan rapi atau bergantian sehingga tidak saling dahulu mendahului antara yang satu dengan yang lain'.

Menurut Siagian sistem antrian adalah himpunan pelanggan, server beserta aturan yang mengatur antara kedatangan pelanggan dan pelayanannya. Antrian terjadi ketika pelanggan yang datang ke suatu pelayanan melebihi kapasitas pelayanan yang tersedia (Ersyad dan Dodi, 2010) [5].

Untuk memberikan kepuasan pelanggan, sebuah sistem selalu berusaha memberikan pelayanan yang terbaik. Pelayanan yang terbaik diantaranya adalah memberikan pelayanan yang cepat sehingga pelanggan tidak dibiarkan menunggu terlalu lama. 


\section{Metode}

Metode multi channel - multi phase adalah sebuah model sistem antrian dalam teori antrian dimana terdapat dua atau lebih antrian maupun pelayanan [2] dalam setiap jalurnya seperti pada gambar sebagai berikut :

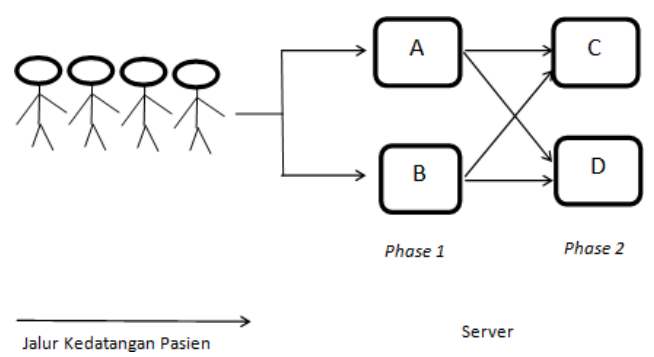

Berikut ini adalah rumus yang digunakan dalam metode multi channel-multi phase :

$\mathrm{P}=\lambda /(1 / \mu)$

$\mathrm{L}=\lambda /(1 / \mu-\lambda)$

$\mathrm{Lq}=\lambda /(1 / \mu(1 / \mu-\lambda))$

$\mathrm{W}=1 /(1 / \mu-\lambda)$

$W q=\lambda /(1 / \mu(1 / \mu-\lambda))$

Keterangan :

$\mathrm{P} \quad=$ Tingkat kesibukan fasilitas pelayanan

$\lambda$ pasien $=$ Jumlah rata-rata tingkat kedatangan pasien

$\lambda$ server $=$ Jumlah rata-rata tingkat kedatangan pasien menujur server

$\mu \quad=$ Rata-rata pelayanan pasien

$1 / \mu \quad=$ Jumlah rata-rata pasien dilayani

L $\quad=J u m l a h$ rata-rata kedatangan yang diharapkan menunggu dalam sistem antrian

Lq =Jumlah kedatangan yang diharapkan menunggu dalam sistem antrian

W =Waktu yang diharapkan oleh setiap kedatangan selama dalam sistem (menunggu pelayanan)

Wq =Waktu yang diharapkan oleh setiap kedatangan untuk menunggu dalam sistem antrian.

Metode pengumpulan data yang digunakan adalah metode observasi yang meliputi waktu-waktu yang dicatat pada saat proses pelayanan terjadi, sedangkan sumber data yang digunakan dalam penelitian ini adalah data primer yaitu hasil pengukuran secara langsung waktu kedatangan pasien, waktu pasien menunggu dalam sistem antrian dan waktu pasien dilayani. Pencatatan waktu dilakukan pada tiap server (layanan) yang akan menjadi data primer untuk dijadikan sebagai dasar penambahan server ( layanan ) pada tiap phase.

Teknik observasi adalah teknik pengumpulan data dengan cara peneliti melakukan pengamatan secara langsung di lapangan tempat lokasi penelitian dilakukan. Pengumpulan data dilakukan dengan melakukan pengamatan langsung dalam waktu satu hari. Alat bantu yang digunakan antara lain lembar observasi tingkat kedatangan dan tingkat pelayanan di loket pendaftaran rawat jalan, stopwatch dan kalkulator. Penelitian ini dilaksanakan di ruang pendaftaran pasien rawat jalan RS Royal Prima, waktu pelaksanaan penelitian pada bulan Agustus 2018. Objek yang diteliti adalah waktu kedatangan (WD), waktu pelayanan (WP), lama waktu tunggu pasien(LT), waktu selesai pelayanan(WK), lama pelayanan (LP) dan alur server pelayanan. Teknik pengambilan sampel dilakukan di loket pendaftaran pasien rawat jalan dengan mengambil sampel pelayanan yang dibutuhkan pada masing-masing tempat pada jenis pelayanan.

Berdasarkan pengumpulan data dilapangan maka diperoleh data pelayanan pasien dalam bentuk tabel sebagai berikut :

TABLE 1

Data Pelayanan PASIEN MENDAFTAR Ke CS (PHASE I)

\begin{tabular}{|c|c|c|c|c|c|c|c|}
\hline No & NAMA & $\begin{array}{c}\text { WD } \\
\text { (waktu } \\
\text { datang) }\end{array}$ & $\begin{array}{c}\text { WP } \\
\text { (waktu } \\
\text { panggil } \\
\text { ) }\end{array}$ & $\begin{array}{l}\text { LT } \\
\text { (lama } \\
\text { tunggu } \\
\text { ) }\end{array}$ & $\begin{array}{c}\text { wK } \\
\text { (waktu } \\
\text { keluar) }\end{array}$ & $\begin{array}{c}\text { LP } \\
\text { (lama } \\
\text { pelayanan } \\
\text { J }\end{array}$ & SERVER \\
\hline \multirow[t]{2}{*}{1} & $\begin{array}{l}\text { Ny. } \\
\text { MULIANAWATI } \\
\text { VASCALIA } \\
\text { SILITONGASH }\end{array}$ & 8:01:29 & 8:05:40 & 4:11 & 8:09:08 & 03:28 & 1 \\
\hline & $\begin{array}{l}\text { Tn. H DAMANG } \\
\text { BAHRIUM } \\
\text { SIREGAR, DRS }\end{array}$ & 8:03:06 & 8:09:17 & 6:11 & 8:11:57 & 02:40 & 2 \\
\hline 3 & $\begin{array}{l}\text { Tn. NADIRSYAH } \\
\text { DRS }\end{array}$ & 8:05:20 & 8:09:08 & 3:48 & 8:10:34 & 01:26 & 1 \\
\hline 4 & Ny. MASITAH & 8:06:05 & 8:11:57 & 5:52 & 8:13:42 & 01:45 & 2 \\
\hline 5 & $\begin{array}{l}\text { Ny. SAURLINA } \\
\text { SIAGIAN }\end{array}$ & 8:06:55 & 8:10:34 & 3:39 & 8:13:23 & 02:49 & 1 \\
\hline 6 & $\begin{array}{l}\text { Tn. LIM A HUAT } \\
\text { ALLAS } \\
\text { AHUWADI }\end{array}$ & 8:08:00 & 8:13:42 & $5: 42$ & 8:15:56 & 02:14 & 2 \\
\hline 7 & Ny. HABIBAH & 8:08:06 & 8:13:23 & $5: 17$ & 8:16:53 & 03:30 & 1 \\
\hline 8 & $\begin{array}{l}\text { Ny. TIPAK BR } \\
\text { SITOMPUL }\end{array}$ & 8:09:01 & 8:15:56 & 6:55 & 8:20:10 & 04:14 & 2 \\
\hline 9 & $\begin{array}{l}\text { Tn. NGADAP } \\
\text { GURUSINGA } \\
\text { SPD }\end{array}$ & 8:11:55 & 8:16:53 & 4:58 & 8:19:11 & 02:18 & 1 \\
\hline 10 & $\begin{array}{l}\text { Ny. SITI } \\
\text { MAISYARAH } \\
\text { SIREGAR }\end{array}$ & 8:13:43 & 8:20:10 & 6:27 & 8:22:50 & 02:40 & 2 \\
\hline 11 & $\begin{array}{l}\text { Ny. NETTY H } \\
\text { TAMBUNAN } \\
\text { SPD }\end{array}$ & 8:14:28 & 8:19:11 & 4:43 & 8:21:17 & 02:06 & 1 \\
\hline 12 & $\begin{array}{l}\text { Ny. SUGIEM M } \\
\text { SARAGIH }\end{array}$ & 8:14:38 & 8:20:50 & 6:12 & $8: 21: 11$ & $00: 21$ & 2 \\
\hline 13 & $\begin{array}{l}\text { Ny. T Y USTINA } \\
\text { GULTOM }\end{array}$ & 8:16:39 & 8:21:17 & 4:38 & 8:23:38 & 02:21 & 1 \\
\hline 14 & $\begin{array}{l}\text { Tn. JALAHAN } \\
\text { SITUMORANG }\end{array}$ & 8:17:40 & 8:21:11 & 3:31 & 8:24:14 & 03:03 & 2 \\
\hline 15 & $\begin{array}{l}\text { Tn. ANWAR } \\
\text { KOMALA }\end{array}$ & 8:17:49 & 8:23:38 & 5:49 & 8:25:30 & 01:52 & 1 \\
\hline 16 & Ny. SUPARTI & 8:18:24 & 8:22:14 & 5:50 & 8:25:20 & 03:06 & 2 \\
\hline 17 & $\begin{array}{l}\text { Ny. KUSUMA } \\
\text { DEWI } \\
\text { NASUTION }\end{array}$ & 8:18:34 & 8:24:30 & 5:56 & 8:26:30 & 02:00 & 1 \\
\hline 18 & $\begin{array}{l}\text { Tn. KARNAIN } \\
\text { JAMBAK }\end{array}$ & 8:19:00 & 8:22:20 & 3:20 & 8:25:40 & 03:20 & 2 \\
\hline 19 & $\begin{array}{l}\text { NY. TIURMA } \\
\text { SIAHAAN }\end{array}$ & 8:19:33 & $8: 26: 30$ & 6:57 & 8:27:59 & 01:29 & 1 \\
\hline 20 & Ny. KAMISAH & 8:21:11 & 8:25:40 & 4:29 & 8:26:27 & 00:47 & 2 \\
\hline
\end{tabular}


TABLE 2

\begin{tabular}{|c|c|c|c|c|c|c|}
\hline No & NAMA & $\begin{array}{l}\begin{array}{l}\text { WD } \\
\text { (waktu } \\
\text { datang) }\end{array} \\
\end{array}$ & $\begin{array}{c}\text { WP } \\
\text { (waktu } \\
\text { panggil) }\end{array}$ & $\begin{array}{c}\text { LT } \\
\text { (lama } \\
\text { tunggu) } \\
\end{array}$ & $\begin{array}{c}\text { Wk } \\
\text { (waktu } \\
\text { keluar) }\end{array}$ & $\begin{array}{c}\text { LP } \\
\text { (lama } \\
\text { pelayanan) }\end{array}$ \\
\hline 1 & $\begin{array}{l}\text { Tn. H DAMANG } \\
\text { BAHRIUM SIREGAR, } \\
\text { DRS }\end{array}$ & 8:11:57 & 8:16:56 & 00:04:59 & 8:25:22 & 0:08:26 \\
\hline 2 & $\begin{array}{l}\text { Ny. SUGIEM M } \\
\text { SARAGIH }\end{array}$ & 8:21:11 & 8:25:22 & 00:04:11 & $8: 27: 41$ & 0:02:19 \\
\hline 3 & $\begin{array}{l}\text { Ny. SITI MAISYARAH } \\
\text { SIREGAR }\end{array}$ & 8:22:50 & 8:27:41 & 00:04:51 & 8:30:07 & 0:02:26 \\
\hline 4 & Ny. SUPARTI & 8:25:20 & 8:30:07 & 00:04:47 & 8:31:10 & 0:01:03 \\
\hline 5 & $\begin{array}{l}\text { Ny. KUSUMA DEWI } \\
\text { NASUTION }\end{array}$ & 8:26:30 & $8: 31: 10$ & 00:04:40 & 8:32:23 & 0:01:13 \\
\hline 6 & $\begin{array}{l}\text { Ny. TIURMA } \\
\text { SIAHAAN }\end{array}$ & 8:27:59 & 8:32:23 & 00:04:24 & 8:33:16 & 0:00:53 \\
\hline 7 & $\begin{array}{l}\text { Ny. ADELINA } \\
\text { SINAGA }\end{array}$ & 8:28:08 & 8:33:16 & 00:05:08 & 8:34:29 & 0:01:13 \\
\hline 8 & $\begin{array}{l}\text { Ny. IFDA HANUM } \\
\text { NASUTION }\end{array}$ & 8:30:12 & 8:34:29 & 00:04:17 & 8:40:23 & 0:05:54 \\
\hline 9 & Ny. ERLIN MATILDA & 8:35:55 & 8:40:23 & 00:04:28 & 8:45:56 & 0:05:33 \\
\hline 10 & Ny. MARIETJE & 8:41:41 & 8:45:56 & 00:04:15 & 8:51:10 & 0:05:14 \\
\hline 11 & $\begin{array}{l}\text { Tn. RAHMATSYAH } \\
\text { BUDI }\end{array}$ & 8:47:00 & 8:51:10 & 00:04:10 & 8:57:38 & 0:06:28 \\
\hline 12 & NY. PAULA WENI & 8:53:05 & 8:57:38 & 00:04:33 & 8:59:14 & 0:01:36 \\
\hline 13 & NY. YUSNIAR & 8:53:17 & 8:59:14 & 00:05:57 & 9:06:14 & 0:07:00 \\
\hline 14 & NY. DBR HOMBING & 9:00:18 & 9:06:14 & 00:05:56 & 9:10:38 & $0: 04: 24$ \\
\hline 15 & NY. HJ NURHANI & 9:05:04 & 9:10:38 & 00:05:34 & 9:11:11 & 0:00:33 \\
\hline 16 & $\begin{array}{l}\text { Ny. SUSANA } \\
\text { TRISTIANTO }\end{array}$ & 9:05:54 & 9:11:11 & 00:05:17 & $9: 16: 34$ & $0: 05: 23$ \\
\hline 17 & $\begin{array}{l}\text { Tn. IKHWAN EFENDY } \\
\text { SIREGAR }\end{array}$ & 9:10:43 & $9: 16: 34$ & 00:05:51 & 9:18:08 & $0: 01: 34$ \\
\hline 18 & $\begin{array}{l}\text { Ny. TEH ABOY } \\
\text { ELVIDA }\end{array}$ & 9:12:17 & 9:18:08 & 00:05:51 & 9:24:37 & 0:06:29 \\
\hline 19 & $\begin{array}{l}\text { Tn. MUHAMMAD } \\
\text { SYAFII }\end{array}$ & 9:19:32 & 9:24:37 & 00:05:05 & 9:25:32 & 0:00:55 \\
\hline 20 & $\begin{array}{l}\text { Ny. MARTHA } \\
\text { ZORAIDAL TOBING }\end{array}$ & 9:19:57 & 9:25:32 & 00:05:35 & 9:31:15 & 0:05:43 \\
\hline
\end{tabular}

TABLE 3

DATA PELAYANAN PASIEN KE POLIKLINIK PENYAKIT SARAF (PHASE II)

\begin{tabular}{|c|c|c|c|c|c|c|}
\hline No & NAMA & $\begin{array}{l}\text { WD } \\
\text { (waktu } \\
\text { datang) }\end{array}$ & $\begin{array}{c}\text { WP } \\
\text { (wakku } \\
\text { panggil) }\end{array}$ & $\begin{array}{c}\text { LT } \\
\text { (lama } \\
\text { tunggu) }\end{array}$ & $\begin{array}{c}\text { WK } \\
\text { (waktu } \\
\text { keluar) }\end{array}$ & $\begin{array}{c}\text { LP } \\
\text { (lama } \\
\text { pelayanan }\end{array}$ \\
\hline 1 & Tn. NADIRSYAH DRS & 8:05:20 & 8:10:07 & 0:04:47 & 8:11:30 & $0: 01: 23$ \\
\hline 2 & $\begin{array}{l}\text { Ny. SAURLINA } \\
\text { SIAGIAN }\end{array}$ & 8:06:55 & 8:11:30 & 0:04:35 & 8:12:45 & 0:01:15 \\
\hline 3 & $\begin{array}{l}\text { Tn. LIMA HUAT } \\
\text { ALIAS AHUWADI }\end{array}$ & 8:08:00 & 8:12:45 & $0: 04: 45$ & 8:13:34 & 0:00:49 \\
\hline 4 & $\begin{array}{l}\text { Ny. TIPAK BR } \\
\text { SITOMPUL }\end{array}$ & 8:09:01 & 8:13:34 & $0: 04: 33$ & 8:16:11 & $0: 02: 37$ \\
\hline 5 & $\begin{array}{l}\text { Tn. NGADAP } \\
\text { GURUSINGA SPD }\end{array}$ & 8:11:55 & 8:16:11 & $0: 04: 16$ & 8:19:10 & 0:02:59 \\
\hline 6 & $\begin{array}{l}\text { Ny. NETYY H } \\
\text { TAMBUNAN SPD }\end{array}$ & 8:14:28 & 8:19:10 & $0: 04: 42$ & 8:22:00 & 0:02:50 \\
\hline 7 & $\begin{array}{l}\text { Tn. JALAHAN } \\
\text { SITUMORANG }\end{array}$ & 8:17:40 & 8:22:00 & 0:04:20 & 8:30:14 & $0: 08: 14$ \\
\hline 8 & $\begin{array}{l}\text { Ny. PINTAULI } \\
\text { SARAGIH }\end{array}$ & 8:25:44 & 8:30:14 & 0:04:30 & 8:41:18 & 0:11:04 \\
\hline 9 & $\begin{array}{l}\text { NY. SHALIMAH } \\
\text { TAMPUBOLON }\end{array}$ & $8: 36: 42$ & 8:41:18 & $0: 04: 36$ & 8:45:44 & $0: 04: 26$ \\
\hline 10 & $\begin{array}{l}\text { Tn. RENWARD } \\
\text { SITORUS SE }\end{array}$ & 8:41:04 & 8:45:44 & 0:04:40 & 8:46:39 & $0: 00: 55$ \\
\hline 11 & Tn. C BANTU PURBA & 8:42:25 & 8:46:39 & $0: 04: 14$ & 8:52:17 & $0: 05: 38$ \\
\hline 12 & $\begin{array}{l}\text { Tn. H MOHD THAHIR } \\
\text { SE }\end{array}$ & $8: 47: 28$ & 8:52:17 & $0: 04: 49$ & 8:59:31 & $0: 07: 14$ \\
\hline 13 & $\begin{array}{l}\text { Ny. HASNAWATI } \\
\text { LUBIS }\end{array}$ & 8:54:39 & 8:59:31 & $0: 04: 52$ & 9:16:35 & $0: 17: 04$ \\
\hline 14 & $\begin{array}{l}\text { Ny. MELVA } \\
\text { MARPAUNG }\end{array}$ & 9:12:07 & $9: 16: 35$ & $0: 04: 28$ & 9:21:13 & $0: 04: 38$ \\
\hline 15 & $\begin{array}{l}\text { Tn. DRS SINGOTAN } \\
\text { SITUNGKIR }\end{array}$ & $9: 15: 42$ & 9:21:13 & $0: 05: 31$ & 9:28:50 & $0: 07: 37$ \\
\hline 16 & $\begin{array}{l}\text { Ny. MARIA D } \\
\text { PANGABEAN }\end{array}$ & 9:23:19 & 9:28:50 & $0: 05: 31$ & 9:33:48 & $0: 04: 58$ \\
\hline 17 & Ny. SALBIAH & 9:28:23 & 9:33:48 & $0: 05: 25$ & 9:38:15 & $0: 04: 27$ \\
\hline 18 & NY. JENNI CHOUDRI & 9:28:32 & 9:38:15 & $0: 09: 43$ & 9:42:41 & $0: 04: 26$ \\
\hline 19 & Ny. HJ FERA LUPINA & 9:29:27 & $9: 42: 41$ & $0: 13: 14$ & 9:44:32 & $0: 01: 51$ \\
\hline 20 & Th. SUHER & 9::38:41 & 9:44:32 & $0: 05: 51$ & 9:46:27 & $0: 01: 55$ \\
\hline
\end{tabular}

Selama pengambilan data di RSU Royal Prima, ditemukan adanya antrian yaitu pasien yang menunggu untuk dilayani oleh CS. Sebelum waktu pelayanan dimulai keadaan RSU Royal Prima tidak ada antrian, setelah pelayanan di buka maka pasien mulai antrian untuk mengambil nomor pendaftaran. Semakin banyak pasien yang datang maka antrian semakin panjang dan kesibukan CS meningkat melayani pasien. Kemudian setelah jam kerja CS selesai maka RSU Royal Prima kembali seperti semula yaitu tidak ada antrian lagi. Keadaan seperti inilah yang disebut steady state. Steady state adalah keadaan yang stabil dimana laju kedatangan kurang dari laju pelayanan [1], memenuhi kondisi steady state maka haruslah rata-rata jumlah pasien yang datang menuju server lebih kecil dari rata-rata laju pelayanan, jika kondisi tersebut tidak terpenuhi maka akan terjadi penumpukan pasien dalam antrian. Untuk itu dilakukan pengujian steady state untuk mengetahui apakah server pelayan perlu ditambah atau tidak sebagai berikut :

1. Pengujian Steady State Phase I

a. Rata-rata tingkat kedatangan ( $\lambda$ pasien)

$$
\begin{aligned}
\lambda_{\text {pasien }} & =\frac{\mathrm{jumlah} \text { pasien selama pengamatan }}{\text { waktu pengamatan }} \\
& =\frac{395}{11} \\
& =35,9 \text { dibulatkan menjadi } 36 \text { pasien } / \mathrm{jam}
\end{aligned}
$$

Jadi rata-rata kedatangan pasien adalah 36 pasien/jam.

b. Kecepatan kedatangan pasien menuju server

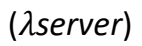

$$
\begin{aligned}
\lambda_{\text {server }} & =\frac{\text { rata-rata kedatangan pasien }}{\text { jumlah server }} \\
& =\frac{36}{2} \\
& =18 \text { pasien } / \mathrm{jam}
\end{aligned}
$$

Jadi rata-rata kedatangan pasien menuju server adalah 18 pasien/jam tiap server.

C. Rata - rata waktu pelayanan pasien

$$
\begin{aligned}
\mu & =\frac{\text { jumlah lama pelayanan }}{\text { jumlahpasien }} \\
& =\frac{1535}{395} \\
& =3,88 \text { dibulatkan menjadi } 4 \text { menit/pasien }
\end{aligned}
$$

Rata-rata waktu pelayanan pasien adalah 4 menit/pasien.

d. Kecepatan kedatangan pasien menuju server

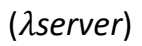

$\lambda_{\text {server }}=\frac{\text { rata-rata kedatangan pasien }}{\text { jumlah server }}$ 


$$
\begin{aligned}
& =\frac{36}{2} \\
& =18 \text { pasien } / \mathrm{jam}
\end{aligned}
$$

Jadi rata-rata kedatangan pasien menuju server adalah 18 pasien/jam tiap server.

e. Kecepatan pelayanan pasien $(1 / \mu)$

$$
\begin{aligned}
1 / \mu & =\frac{1}{60} \frac{1}{\text { rata-rata } \text { waktu pelayanan }} \\
& =\frac{4}{4} \\
& =15 \text { pasien } / \mathrm{jam}
\end{aligned}
$$

Jadi rata-rata kecepatan pelayanan pasien adalah 15 pasien/jam.

Jumlah rata-rata tingkat kedatangan pasien 36 orang/jam, pelayanan yang diberikan kepada pasien yang datang rata-rata 4 menit/orang dan jumlah bagian pendaftaran yang buka pada jam sibuk adalah 2 pintu. Berikut adalah data yang telah diperoleh :

$$
\begin{array}{ll}
\lambda=36 / 2 & =18 \text { orang } / \mathrm{jam} \\
1 / \mu=60 / 4 & =15 \text { orang } / \mathrm{jam}
\end{array}
$$

Dari data yang telah diperoleh dapat dilihat bahwa kondisi steady state tidak terpenuhi dimana laju kedatangan pasien lebih besar daripada laju pelayanan pasien, seperti dilihat dari hasil perhitungan sebagai berikut :

$\begin{array}{ll}\text { Laju kedatangan pasien }(\lambda) & =36 / 2 \\ & =18 \text { orang } / \mathrm{jam} \\ \text { Laju pelayanan pasien }(1 / \mu) & =60 / 4 \\ & =15 \text { orang } / \mathrm{jam} \\ \text { Kesimpulan } & =\lambda>1 / \mu\end{array}$

f. Penambahan server pelayanan

Dengan penambahan 1 server pelayanan menjadi 3 server pelayanan pada phase I costumer service maka steady state dapat terpenuhi sebagai berikut :

$$
\begin{array}{ll}
\lambda=36 / 3 & =12 \text { orang } / \mathrm{jam} \\
1 / \mu=60 / 4 & =15 \text { orang } / \mathrm{jam}
\end{array}
$$

2. Pengujian Steady State Phase II (pelayanan penyakit dalam)

a. Rata-rata tingkat kedatangan ( $\lambda$ pasien)

$$
\begin{aligned}
\lambda_{\text {pasien }} & =\frac{\mathrm{jumlah} \text { pasien selama pengamatan }}{\text { waktu pengamatan }} \\
& =\frac{106}{11} \\
& =9,6 \text { dibulatkan menjadi } 10 \text { pasien } / \mathrm{jam}
\end{aligned}
$$

Jadi rata-rata kedatangan pasien adalah 10 pasien/jam.

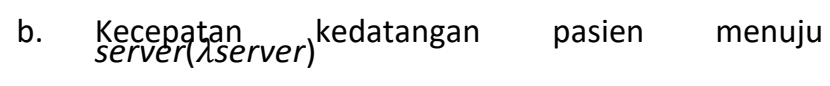

$$
\begin{aligned}
\lambda_{\text {server }} & =\frac{\text { rata-rata kedatangan pasien }}{\text { jumlah server }} \\
& =\frac{1}{1} \\
& =10 \text { pasien } / \mathrm{jam}
\end{aligned}
$$

Jadi rata-rata kedatangan pasien menuju server adalah 10 pasien/jam tiap server.

c. Kecepatan Pelayanan Pasien $(1 / \mu)$

$$
\begin{aligned}
\mu & =\frac{j \text { umlah lama pelayanan }}{\mathrm{jumlah} \text { pasien }} \\
& =\frac{620}{106} \\
& =5,8 \text { dibulatkan menjadi } 6 \text { menit/pasien }
\end{aligned}
$$

Rata-rata waktu pelayanan pasien adalah 6 menit/pasien.

d. Kecepatan pelayanan pasien $(1 / \mu)$ adalah sebagai berikut :

$$
\begin{aligned}
1 / \mu & =\frac{1}{60} \frac{1}{\text { rata-rata } \text { waktu pelayanan }} \\
& =\frac{6}{6} \\
& =10 \text { pasien } / \mathrm{jam}
\end{aligned}
$$

Jadi rata-rata kecepatan pelayanan pasien adalah 10 pasien/jam.

Jumlah rata-rata tingkat kedatangan pasien 10 orang/jam, pelayanan yang diberikan kepada pasien yang datang rata-rata 6 menit/orang dan jumlah bagian pelayanan yang buka pada jam sibuk adalah 1 pintu. Berikut adalah data yang telah diperoleh :

$\begin{array}{ll}\lambda=10 / 1 & =10 \text { orang } / \mathrm{jam} \\ 1 / \mu=60 / 6 & =10 \text { orang } / \mathrm{jam}\end{array}$

Dari data yang telah diperoleh dapat dilihat bahwa kondisi steady state tidak terpenuhi dimana laju kedatangan pasien sama dengan laju pelayanan pasien, seperti dilihat dari hasil perhitungan sebagai berikut :

$$
\begin{array}{ll}
\text { Laju kedatangan pasien }(\lambda) & =10 / 1 \\
& =10 \text { orang } / \mathrm{jam} \\
\text { Laju pelayanan pasien }(1 / \mu) & =60 / 6 \\
& =10 \text { orang } / \mathrm{jam} \\
\text { Kesimpulan } & =\lambda=1 / \mu
\end{array}
$$

e. Penambahan server pelayanan

Dengan penambahan 1 server pelayanan menjadi 2 server pelayanan pada phase II poliklinik penyakit dalam maka steady state dapat terpenuhi sebagai berikut : 
$\lambda=10 / 2$

$=6$ orang $/ \mathrm{jam}$

$1 / \mu=60 / 6$

$=10$ orang $/ \mathrm{jam}$

\section{Hasil}

Setelah melakukan perhitungan / pengujian steady state maka didapat data sebagai berikut :

Jumlah pasien

$=395$ pasien

Waktu pengamatan

$=11 \mathrm{jam}$

Jumlah server pada phase I

$=2$ server

Jumlah server pada phase II

$=2$ server

a. Hasil Pengujian Steady State Phase I

Jumlah rata-rata tingkat kedatangan pasien ke rumah sakit adalah 36 orang/jam, pelayanan yang diberikan kepada pasien yang datang rata-rata 4 menit/orang dan jumlah bagian pendaftaran yang buka adalah 2 pintu. Berikut adalah data yang telah diperoleh :

$$
\begin{array}{ll}
\lambda=36 / 2 & =18 \text { orang } / \mathrm{jam} \\
1 / \mu=60 / 4 & =15 \text { orang } / \mathrm{jam}
\end{array}
$$

Dari data yang telah diperoleh dapat dilihat bahwa kondisi steady state phase I tidak terpenuhi dimana laju kedatangan pasien lebih besar daripada laju pelayanan pasien, seperti dilihat dari hasil perhitungan sebagai berikut :

$$
\begin{aligned}
\text { Laju kedatangan pasien }(\lambda) & =36 / 2 \\
& =18 \text { orang } / \mathrm{jam} \\
\text { Laju pelayanan pasien }(1 / \mu) & =60 / 4 \\
& =15 \text { orang } / \text { jam } \\
\text { Kesimpulan } & =\lambda>1 / \mu
\end{aligned}
$$

Dengan penambahan 1 server pelayanan menjadi 3 server pelayanan pada phase I maka steady state dapat terpenuhi sebagai berikut :

$$
\begin{array}{ll}
\lambda=36 / 3 & =12 \text { orang } / \mathrm{jam} \\
1 / \mu=60 / 4 & =15 \text { orang } / \mathrm{jam} \\
\text { Kesimpulan } & =\lambda<1 / \mu
\end{array}
$$

b. Hasil Pengujian Steady State Phase II Jumlah rata-rata tingkat kedatangan pasien 10 orang/jam, pelayanan yang diberikan kepada pasien yang datang rata-rata 6 menit/orang dan jumlah bagian pelayanan yang buka pada jam sibuk adalah 1 pintu. Berikut adalah data yang telah diperoleh :

$$
\begin{array}{ll}
\lambda=10 / 1 & =10 \text { orang } / \mathrm{jam} \\
1 / \mu=60 / 6 & =10 \text { orang } / \mathrm{jam}
\end{array}
$$

Dari data yang telah diperoleh dapat dilihat bahwa kondisi steady state phase II tidak terpenuhi dimana laju kedatangan pasien sama dengan laju pelayanan pasien, seperti dilihat dari hasil perhitungan sebagai berikut :

$\begin{array}{ll}\text { Laju kedatangan pasien }(\lambda) & =10 / 1 \\ & =10 \text { orang } / \mathrm{jam} \\ \text { Laju pelayanan pasien }(1 / \mu) & =60 / 6 \\ & =10 \mathrm{orang} / \mathrm{jam} \\ \text { Kesimpulan } & =\lambda=1 / \mu\end{array}$

Dengan penambahan 1 server pelayanan menjadi 2 server pelayanan pada phase II poliklinik penyakit dalam maka steady state dapat terpenuhi sebagai berikut :

$\begin{array}{ll}\lambda=10 / 2 & =6 \text { orang } / \mathrm{jam} \\ 1 / \mu=60 / 6 & =10 \text { orang } / \mathrm{jam} \\ \text { Kesimpulan } & =\lambda<1 / \mu\end{array}$

\section{Implementasi}

Dalam penerapan sistem antrian registrasi multi channel - multi phase, diperlukan sistem aplikasi dalam penerapannya agar dapat berjalan dengan baik. Dalam sistem antrian yang telah dibuat, pengguna yang dapat menggunakan sistem antrian ini dikelompokkan menjadi dua bagian yaitu :

1. Pasien, yaitu pengguna yang hanya dapat mengambil nomor antriandalam sistem antrian, dan masuk dalam sistem antrian menunggu sampai nomor antrian yang dimiliki pasien dipanggil.

2. User, yaitu pengguna yang dapat melakukan pemanggilan terhadap nomor antrian pasien untuk pelayanan pendaftaran dan juga untuk pelayanan konsultasi degan dokter di poliklinik.

Langkah -langkah menggunakan sistem antrian yang dirancang adalah sebagai berikut :

1. Login dengan memasukkan username dan password

2. Setelah login berhasil akan diarahkan ke form panggil nomor antrian, klik panggil antrian kemudian muncul form konfirmasi pelayanan.

3. Pada form konfirmasi pelayanan, akan muncul 2 tombol, tombol layani antrian dan batal antrian, untuk melakukan pendaftaran pasien klik tombol layani antriankemudian untuk membatalkan nomor antrian klik tombol batalkan antrian. Jika tombol layani antrian di klik maka muncul 2 tombol, yaitu tombol penyakit dalam dan tombol penyakit syaraf untuk melanjutkan ke sistemantrianphase II.

4. Setelah memilih tujuan poli di phase I menuju poliklinik (phase II) maka nomor tersebut bisa dipanggil oleh perawat poliklinik melalui form panggil nomor antrian poliklinik atau phase II.

5. Setelah user di poliklinik berhasil login akan diarahkan ke form panggil nomor antrian, klik panggil antrian kemudian muncul form konfirmasi pelayanan. 
6. Pada form konfirmasi pelayanan, akan muncul 2 tombol, tombol layani antrian dan batal antrian, untuk melakukan pendaftaran pasien klik tombol layani antriankemudian untuk membatalkan nomor antrian klik tombol batalkan antrian. Jika tombol layani antrian di klik maka sistem antrian akan berakhir di phase II.

a. Tampilan Pengambilan Nomor Antrian Tampilan halaman ambil nomor antrian adalah halamanyang berfungsi untuk memberikan nomor antrian baru, berikut adalah tampilan halaman ambil nomor antrian :

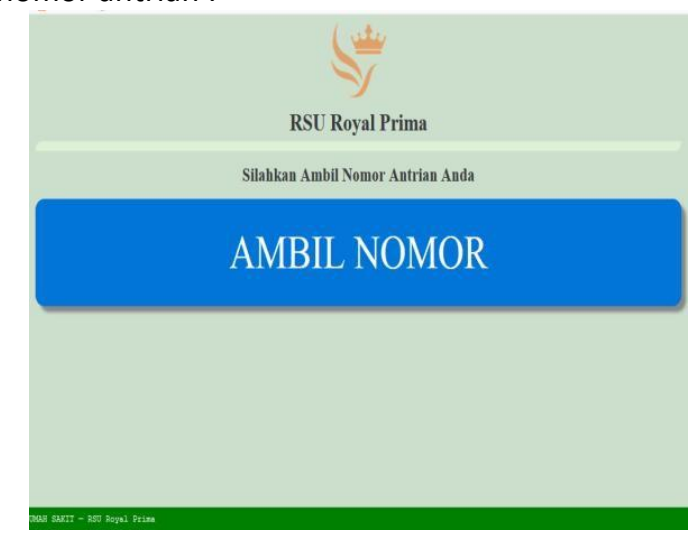

Gambar 1. Halaman ambil Nomor Antrian

\section{b. Karcis Nomor Antrian}

Ketika tombol "ambil nomor" di tekan maka nomor antrian baru akan tercetak melalui printer yang telah disediakan berupa karcis. Tampilan karcis nomor antrian yang dirancang adalah sebagai berikut :

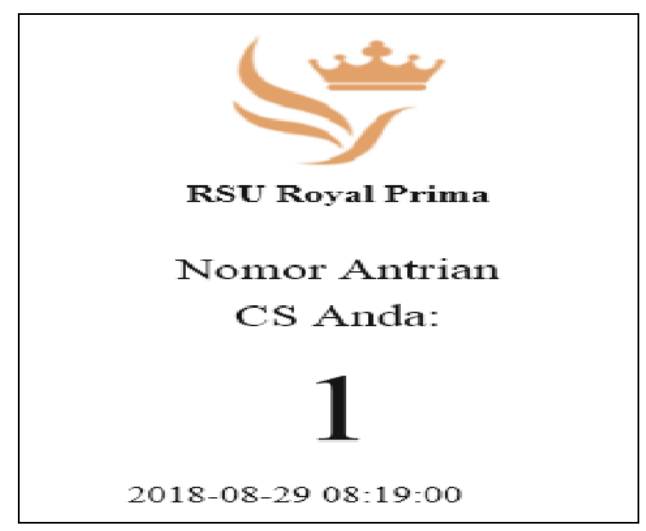

Gambar 2. Karcis Nomor Antrian

c. Halaman Login

Halaman login adalah halaman untuk masuk ke dalam sistem antrian.

Program Studi Teknik Informatika

Universitas Prima Indonesia (UNPRI) Medan

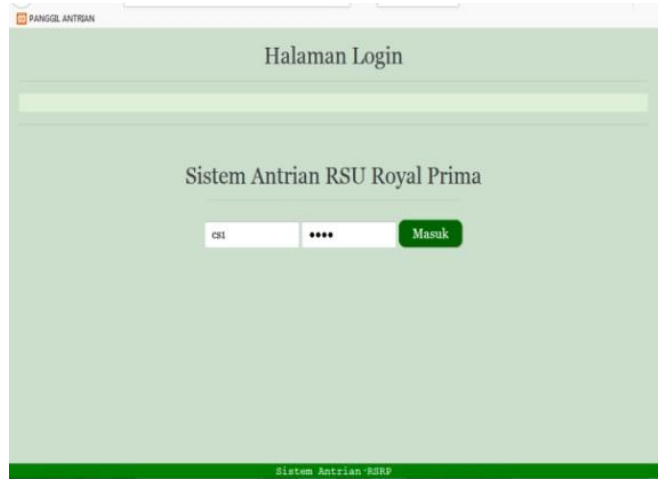

Gambar 3. Halaman Login

d. Halaman Panggil Nomor Antrian

Setelah berhasil masuk ke dalam sistem antrian, maka dapat memanggil nomor antrian.

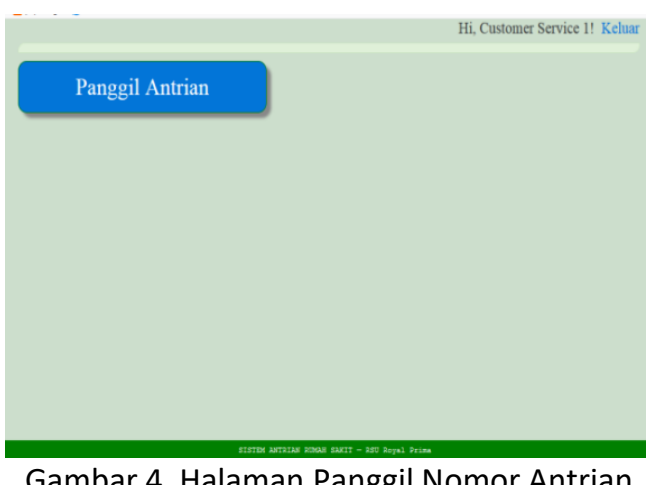

e. Halaman Konfirmasi Pelayanan

Halaman konfirmasi pasien adalah halaman untuk konfirmasi pelayanan untuk melakukan pelayanan.

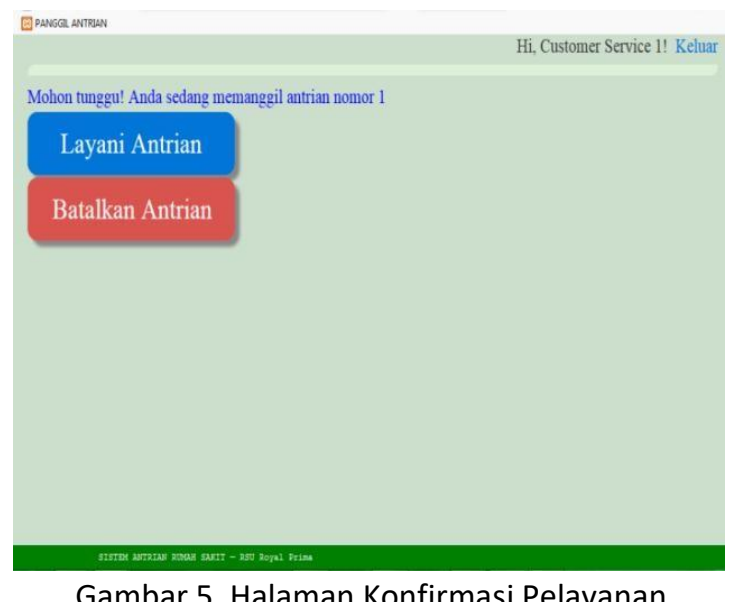

f. Halaman Pilih Pelayanan Ke Phase II

Setelah pasien datang dan tombol layani antrian di klik oleh petugas costumer service maka akan muncul halaman pilih pelayanan untuk menuju ke antrian 
selanjutnya atau phase II, seperti gambar berikut ini :

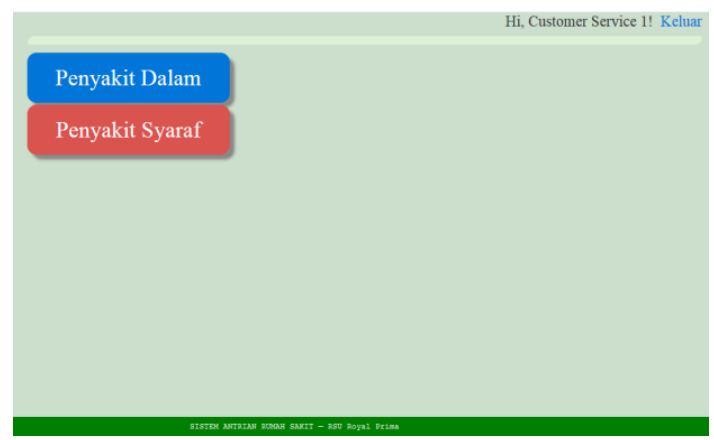

Gambar 6. Halaman Pilih Pelayanan ke Phase II

\section{g. Pelayanan Nomor Antrian Poliklinik}

Ketika tombol panggil antrian di klik secara bersamaan pada halaman informasi pelayanan nomor antrian pelayanan poliklinik, muncul nomor antrian yang sedang dipanggil pada layar monitor yang telah disediakan dan melalui speaker keluar panggilan antrian berupa suara nomor antrian yang sedang dipanggil seperti gambar berikut ini :

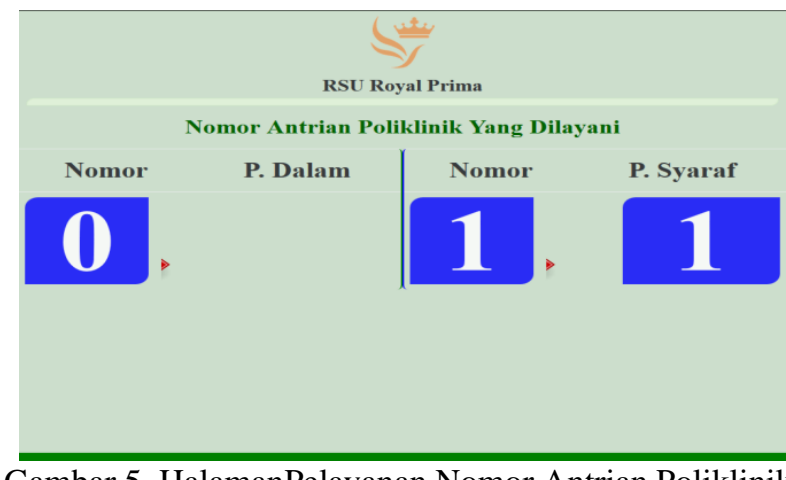

Gambar 5. HalamanPelayanan Nomor Antrian Poliklinik

\section{Kesimpulan}

1. Antrian pasien yang sebelumnya panjang akan berkurang karena efesiensi waktu dan disiplin antri yang secara otomatis diterapkan ke pasien melalui sistem antrian multi channel - multi phase

2. Aplikasi mampu membuat nomor antrian secara otomatis dengan satu sumber kedatangan antrian dengan lebih dari satu tempat pelayanan dan lebih dari satu layanan.

3. Aplikasi sistem antrian yang dihasilkan dapat diatur sesuai dengan jumlah dan jenis layanan yang dibutuhkan. Jika terjadi perkembangan layanan di rumah sakit maka akan memungkinkan dilakukan penambahan server layanan untuk melayani pasien sesuai kebutuhan rumah sakit dan banyaknya pasien yang datang

4. Untuk mengatasi antrian yang banyak dilakukan pengujian steady state maka dapat dihitung tingkat kesibukan suatu server pelayanan sehingga jika suatu server pelayanan sangat sibuk maka server pelayanan tersebut dapat ditambah

5. Diharapkan aplikasi sistem antrian ini dapat dikembangkan menjadi beberapa phase lagi sampai pasien pulang hingga sistem multi channel - multi phase menjadi sempurna

6. Diharapkan aplikasi ini dapat diimplementasikan juga untuk semua tempat atau jenis usaha yang membutuhkan sistem antrian

7. Diharapkan agar aplikasi ini dapat dikembangkan agar semua poliklinik dapat memakai sistem antrian

8. Display antrian diharapkan dapat menampilkan informasi seperti tayangan televisi sebagai media hiburan bagi pasien selama menunggu antrian.

9. Diharapkan pada phase I untuk pendaftaran pasien dapat dilakukan sendiri oleh pasien dengan sistem check in dan booking jam pelayanan.

\section{References}

[1] Siti Aminah, Marisi Aritonang, Evy Sulistianingsih. Analisis antrian multi channel multi phase pada antrian pembuatan surat izin mengemudi dengan model antrian $(\mathrm{mmc})(\mathrm{gd} \infty \infty)$. Buletin IImiah Mat. Stat. dan Terapannya (Bimaster), 2015, 04(2),127 134.

[2] Dedy Purnawan, Putriaji Hendikawati, Much Aziz Muslim. Analisis model antrian perbaikan sepeda motor dengan menggunakan program visual basic. Unnes Journal Of Mathematics, 2013, 2(1), 40-43.

[3] Sofi Nur Rochmawati, Firman Nurdiyansyah. Aplikasi penentuan nomor urut antrian rumah sakit melalui sms gateway. Journal of Information Technology and Computer Science (JOINTECS), 2017, 1(2),1-2.

[4] Noor Saif Muhammad Mussafi. Pemodelan sistem antrian multi-channel jasa teller pada bank syariah di yogyakarta untuk meningkatkan kinerja perusahaan. AdMathEdu, 2015, 5(2), 142-145.

[5] Idanny Mawarny Butar-Butar. Perancangan simulasi antrian pembayaran rekening listrik dengan model multiple channel single phase menggunakan metode multilevel queue. Jurnal Pelita Informatika, 2017, 16(3), 281.W.-K. Chen, Linear Networks and Systems, Belmont, CA: Wadsworth, 1993, pp. 123135.

[6] Toibah Umi Kalsum, Siswanto. Sistem antrian pada puskesmas suka merindu. Jurnal Media Infotama, 2012, 8(1), 45-46.

[7] F.A. Mukarrama, Nur'Eni, Fadjryani. Sistem antrian single channel - multiple phase dalam meningkatkan pelayanan pembayaran pajak kendaraan bermotor di kantor sistem administrasi manunggal satu atap (samsat) kota palu. Natural Science : Journal of Science and Technology, 2017, 6(2), 176-179. 
[8] Edi Winarto, Ali Zaki. Buku sakti pemrograman PHP. Jakarta: PT Elex Media Komputindo.

[9] Betha Sidik. Menggunakan framework code igniter 2.z untuk memudahkan pemrogaman aplikasi web dengan php 5. Bandung: Informatika. 